\title{
Los consorcios ante un nuevo régimen jurídico
}

\author{
Concepción Barrero Rodríguez
}

Catedrática de Derecho Administrativo.

Universidad de Sevilla

\begin{abstract}
SUMARIO: I. GONSIDERACIÓN PREVIA. II. LA SITUACIÓN DE PARTIDA: LA LEY BÁSICA DE RÉGIMEN LOCAL Y LA LEY 30/1992 ANTES DE SU MODIFICACIÓN POR LA LEY 27/2013. III. EL NUEVO MARCO NORMATIVO DE LOS CONSORCIOS. 1. La Ley 27 /2013, de Racionalización y sostenibilidad de la Administración local. Una norma decisiva en la configuración actual del consorcio. 1.1. La Disposición Adicional $20^{\text {a }}$ de la LRJ-PAC. 1.2. Las modificaciones introducidas en los consorcios locales. 1.3. Consideración final. 2. La Ley 15/2014, de reforma del sector público. La confirmación del camino iniciado. 2.1. El derecho de separación de los miembros del consorcio. 2.2. La liquidación del consorcio. 2.3. Plazo de adaptación de los estatutos y Derecho supletorio. 2.4. Valoración final. IV. EL PUNTO FINAL, HASTA AHORA: LA LEY 40/2015 DE RÉGIMEN JURÍDICO DEL SEGTOR PÚBLICO. 1. Algunas notas sobre la configuración de la entidad. 2. El sistema de fuentes. 3. El régimen de adscripción. 4. La creación del consorcio. 5. El contenido de los estatutos. 6. El derecho de separación y la liquidación del consorcio. V. BREVE CONSIDERACIÓN FINAL
\end{abstract}

\section{RESUMEN:}

La reforma del sector público de los últimos años ha afectado de forma importante a los consorcios, cuyo régimen jurídico básico se ha ampliado notablemente, se ha impuesto su adscripción a alguna de las Administraciones que lo integran y se han incorporado nuevos requisitos para su constitución.

PALABRAS CLAVES:

Sector público, Consorcio. 


\section{ABSTRACT:}

The public sector reform in recent rush has affected significantly to consortia whose basic legal regime has widened dramatically, has imposed its attachment to any of the Administrations that integrate and incorporated new requirements for constitution.

\section{KEYWORDS:}

Public sector, consortia.

\section{CONSIDERACIÓN PREVIA ${ }^{1}$}

La reforma del sector público, uno de los objetivos fundamentales del Gobierno en la legislatura recién concluida, ha tenido una proyección importante en el ámbito de los consorcios, toda vez que las distintas Leyes que la han ido concretando han incidido en su tradicional regulación en términos llamados, al menos en teoría, a cambiar la imagen de esta entidad y, quizás, a reducir su amplio número tras la extraordinaria proliferación de los últimos años, propiciada, en buena medida, por la propia indefinición en la que nuestras normas la habían situado y la consiguiente disponibilidad con la que las Administraciones Públicas han contado para su constitución y definición de su régimen jurídico propio.

El análisis y valoración de la nueva regulación del consorcio ha de partir lógicamente de la exposición de los rasgos más destacados de la normativa que se reforma.

\section{LASITUAGIÓNDE PARTIDA: LALEYBÁSICADERÉGIMEN LOCAL Y LA LEY 30/1992 ANTES DE SU MODIFICACIÓN POR LA LEY 27/2013}

Prescindiendo de otros antecedentes más antiguos, puede afirmarse que la regulación del consorcio objeto de modificación por las normas más recientes es la constituida, a nivel estatal, por la Ley 7/1985, de 2 de abril, reguladora de las Bases del Régimen local (LBRL), así como por la Ley 30/1992, de 27 de noviembre, del Régimen jurídico de las Administraciones Públicas y del Procedimiento Administrativo común (LRJ-PAG).

Este trabajo tiene su origen en la ponencia impartida bajo el título "Los consorcios y las fundaciones" en el Simposio sobre la Reforma administrativa, organizado por la Universidad Pompeu Fabra los días 3 y 4 de marzo de 2016. 
La LBRL, en primer término, dedica al consorcio su artículo 87 que, con precedentes claros en el 37.1 del Reglamento de Servicios de las Corporaciones Locales de 17 de junio de 1955, magníficamente analizado, en su día, por J.L. MARTINEZ LÓPEZ-MUÑIZ", permite a las entidades locales "constituir consorcios con otras Administraciones Públicas para fines de interés común o con entidades privadas sin ánimo de lucro que persigan fines de interés público concurrentes con los de las Administraciones Públicas". El artículo 57 de la propia norma, con el que este precepto guarda estrecha conexión, hace expresa alusión al consorcio como instrumento para "la cooperación económica, técnica y administrativa entre la Administración local y las Administraciones del Estado y de las Comunidades Autónomas", cooperación que "se desarrollará con carácter voluntario". El artículo 110 del Real Decreto Legislativo 781/1986, de 18 de abril, de disposiciones vigentes en materia de Régimen local, reitera la capacidad de las entidades locales para constituir consorcios, a los que atribuye "personalidad jurídica propia", y remite a sus estatutos la determinación de sus fines "así como las particularidades del régimen orgánico, funcional y financiero", teniendo siempre en cuenta que sus órganos de decisión habrán de estar "integrados por representantes de todas las Entidades consorciadas". Ese mismo precepto permite finalmente que el consorcio pueda utilizar para la gestión de los servicios de su competencia "cualquiera de las formas previstas en la legislación de Régimen local"3.

Años más tarde, la reforma de la LRJ-PAC por la Ley 4/1999, de 13 de enero, introdujo, con clara inspiración en la norma reguladora del régimen local, un nuevo apartado en el artículo 6 , el $5^{\circ}$, en el que el consorcio aparece, junto con la sociedad mercantil, como una de las formas posibles que puede adoptar esa "organización común” necesaria, en su caso, para la gestión de un convenio. El precepto remite además a los estatutos la determinación de los fines de la entidad, así como las particularidades de su régimen orgánico, funcional y financiero, con una única limitación, la que impone que sus órganos de decisión estén "integrados por representantes de todas las entidades consorciadas" en la proporción que fijen los propios estatutos. E igualmente reconoce la posibilidad de que el consorcio pueda utilizar, para "la gestión de los servicios que se le encomienden", cualquiera "de las formas previstas en la legislación aplicable a las Administraciones consorciadas". Con la LRJ-PAC se produce lo que vino a calificarse como la "deslocalización" del consorcio en referencia a la operación

${ }^{2}$ Los Consorcios en el Derecho español (Análisis de su naturaleza jurídica), IEAL, Madrid, 1974.

3 La parquedad de esta regulación alimenta el debate sobre la naturaleza jurídica de la entidad, acrecentado además por el hecho de que el artículo 3 de la LBRL no lo incluya en su listado de entidades locales. Al respecto pueden verse los estudios de E. NIETO GARRIDO El Consorcio administrativo (Cedecs, Barcelona, 1997, págs. 102-104) y "La Ley de Racionalización y Sostenibilidad de la Administración Local y los consorcios administrativos" (CARRILLO DONAIRE, J.A. y P. NAVARRO RODÍGUEZ (Coors), La reforma del régimen jurídico de la Administración Local. El nuevo marco regulatorio a la luz de la Ley de racionalización y sostenibilidad de la Administración local, La Ley. El Consultor de los Ayuntamientos, Madrid, 2014, págs. 368-371). 
consistente en sacarlo "del mundo local" ". De esta forma queda ya expresamente reconocida la facultad de todas las Administraciones Públicas para constituir consorcios en el marco de las relaciones de colaboración consustanciales al Estado descentralizado que establece la Constitución.

Esta normativa estatal será objeto, en algunos casos, de complemento por el ordenamiento autonómico del que, con carácter general, puede afirmarse, no obstante, su clara opción en favor de la determinación del régimen del consorcio en los propios estatutos de cada una de las entidades creadas ${ }^{5}$.

En este contexto normativo, el consorcio, que ya R. MARTÍN MATEO había calificado en 1992 como "una institución en auge", prolifera extraordinariamente", consolidándose como una entidad absolutamente versátil, dada, de una parte, las amplias posibilidades que ofrece en su propia composición subjetiva y, de otra, su adscripción al servicio de lo más diversos fines. Los consorcios se convierten así en una entidad que vale tanto para prestar servicios municipales básicos como para el desarrollo de objetivos diferentes que exceden del ámbito específico de la competencia municipal por implicar a las de otras instancias; una fórmula idónea para la satisfacción de un objetivo coyuntural, pero, también, una entidad válida para el desempeño de cometidos permanentes en el tiempo. Así puede comprobarse en los datos que aporta "el inventario de entes del sector público estatal, autonómico y local” de la Intervención General del Estado ${ }^{8}$.

4 F. TOSCANO GIL, Los Consorcios metropolitanos, Fundación Democracia y Gobierno Local. Instituto Andaluz de Administración Pública, Madrid-Barcelona, 2001, pág. 34.

No obstante, y como ya había señalado E. NIETO, la deslocalización, en realidad, se había producido años antes, a nivel autonómico. Concretamente, con la Ley catalana 13/1989, de 14 de diciembre, de organización, procedimiento y régimen jurídico de la Administración de la Generalidad, que en su artículo 55 faculta al Gobierno para "acordar la constitución de consorcios entre la Generalidad y otras administraciones públicas para finalidades de interés común o con entidades privadas sin ánimo de lucro que tengan finalidades de interés público concurrentes con las de la Administración” (El Consorcio administrativo, op. cit., pág. 62).

5 Un ejemplo de regulación del consorcio a nivel autonómico puede encontrarse en Andalucía en su Leyes 9/2007, de 22 de octubre, de Administración de la Junta de Andalucía (artículo 12) y 5/2010, de 11 de junio, de Autonomía local (artículos 78-82).

6 En expresión del propio título del artículo "Los consorcios locales: una institución en auge" publicado en el número 129 de 1992 de la Revista de Administración Pública, págs. 397 y ss.

7 Como puede comprobarse, entre otros documentos, en los datos ofrecidos por el "Informe trimestral de seguimiento de las medidas de la Comisión para la Reforma de las Administraciones Públicas" de la "Oficina para la ejecución de la reforma de la Administración" correspondiente al 3 trimestre de 2015, que señala que "entre 2005 y 2011, el número de empresas, fundaciones y consorcios públicos pasó de 3228 a 4036. Es decir, se crearon 808, y ello en los ejercicios de mayor incidencia de la crisis financiera y presupuestaria".

${ }^{8}$ A fecha 31 de diciembre de 2015, en el ámbito estatal existen, entre los 18 que figuran inscritos, 
Esta es, someramente descrita, la regulación normativa y la propia realidad sobre la que se proyecta el importante proceso de reforma del consorcio que culmina con la Ley 40/2015, de 1 de octubre, de Régimen Jurídico del Sector Público (LRJSP).

consorcios, en algunos ejemplos extraídos al azar, para fomentar e impulsar las relaciones de España con los países de la ribera mediterránea, como es el caso del "Consorcio Casa del mediterráneo", o árabes, objeto del "Consorcio Casa árabe"; para gestionar actividades logísticas y empresariales en la bahía de Cádiz ("Consorcio de actividades logísticas, empresariales, tecnológicas, ambientales y de servicios de la bahía de Cádiz"); o para "establecer una estructura de soporte a la investigación clínica con el fin de promover la salud y el bienestar de los ciudadanos ("Consorcio de apoyo a la investigación biomédica en red de unidades centrales de investigación clínica y ensayos clínicos").

Si centramos la atención en el ámbito autonómico, encontramos que, por ejemplo, en Andalucía, con fecha 1 de julio de 2015, existían más de cien consorcios, muchos de ellos constituidos con la finalidad de "contribuir a un desarrollo equilibrado y sostenido del territorio que conforman todos los ayuntamientos integrantes del mismo" "“Consorcio Unidad territorial, empresarial y desarrollo local y técnico" del "Aljarafe" o "la comarca de la Janda) o de "fomentar el empleo y el desarrollo local y tecnológico en Andalucía" ("Consorcios "Marquesado Granada" o de la "Comarca Guadiato)". Existen igualmente varios "Consorcios de Transporte metropolitano". Así los del "Campo de Gibraltar", el "Área de Córdoba" o el "Área de Sevilla". Y los hay finalmente al servicio de otros fines diversos como, por ejemplo, la "ejecución del proyecto de creación del centro Federico García Lorca en la ciudad de Granada ("Consorcio Centro Federico García Lorca"); la "formación de profesionales artesanos y difusión del mercado del mármol" ("Consorcio Escuela del mármol de Fines"); "la gestión de los recursos patrimoniales" ("Consorcio centro Albayzin"); la gestión de una orquesta y promoción de sus actividades ("Consorcio orquesta de la ciudad de Málaga" o "Consorcio Teatro Real Maestranza y Salas del Arenal de Sevilla"); o la implantación de "la sociedad de la información y el conocimiento" (Consorcio Fernando de los Rios"). Esta misma diversidad de fines se aprecia, por ofrecer los datos de otra zona del territorio del Estado, en los consorcios existentes en la Comunidad de Cataluña en donde existen igualmente entidades de esta naturaleza para la satisfacción de fines muy heterogéneos. Así: la gestión del transporte ("Consorcio de Transporte público del área de Girona"); el desarrollo de actividades sanitarias ("Consorcio "hospitalario de Vic"); la gestión urbanística (Consorcios "para el desarrollo del ARE Can Duran" o "Ribera-Salines") o la prestación de servicios sociales ("Consorcio de Servicios sociales de Barcelona"). Y los hay, de igual forma, para la gestión de objetivos muchos más concretos. Así, y entre otros, para "gestionar y fomentar la cultura musical en Catalunya" ("Consorcio Palau de la música catalana"); "reconstruir, conservar y mantener las instalaciones del Gran Teatro Liceo" ("Consorcio Gran Teatro del Liceo"); "la restauración, conservación y promoción del Patrimonio mundial de la Vall da Boi" ("Consorcio Patrimonio mundial de la Vall da Boi”) o la gestión y explotación de un centro de recursos forestales ("Consorcio Centro Tecnológico forestal de Catalunya").

$\mathrm{El}$ análisis finalmente de los datos aportados por ese mismo inventario sobre los consorcios locales revela, aquí también, como estamos ante una entidad adscrita a la satisfacción de intereses muy diferentes, como lo confirman los consorcios existentes en las provincias, por ejemplo, de Barcelona o Sevilla, en las que aparecen consorcios para la prestación de servicios como los de abastecimiento de aguas ("Consorcio Abastecimiento aguas Plan Ecija" o "Consorcio Aguas Sierra Sur") o recogida de residuos ("Consorcio de Residuos sólidos urbanos del Maresme"); la defensa y promoción del medio ambiente ("Consorcio Vía verde de los Alcolres y Escarpe"); o la promoción del turismo ("Consorcio Turismo del Vallés occidental"). 


\section{EL NUEVO MARGO NORMATIVO DE LOS GONSORGIOS}

El ordenamiento actual de los consorcios tiene su origen en la Ley 27/2013, de 27 de diciembre, de Racionalización y sostenibilidad de la Administración local (LR$\mathrm{SAL}$ ), que es la que inicia un proceso de modificación del régimen de la entidad que continúa con la Ley 15/2014, de 16 de septiembre, de Racionalización del sector público y otras medidas de reforma administrativa (LRSP) y que la reciente LRJSP no viene sino a culminar. Este conjunto de disposiciones, surgido al calor del proceso de reforma de las estructuras administrativas comprometido con la Unión europea e imbuido de principios de índole financiera y presupuestaria, va a conformar un nuevo régimen para los consorcios caracterizado por un incremento considerable de la normativa básica estatal reguladora de la figura.

\section{La Ley 27/2013, de Racionalización y sostenibilidad de la Administración local. Una norma decisiva en la configura- ción actual del consorcio.}

Con el objetivo, confesado en su Preámbulo, de "racionalizar la estructura organizativa de la Administración local de acuerdo con los principios de eficiencia, estabilidad y sostenibilidad financiera", esta disposición emprende un proceso de reforma de esta entidad que las Leyes posteriores no vienen sino a completar. La incidencia de esta ley en la regulación de esta figura es doble, en la medida en que afecta no sólo a los consorcios locales, sino que se proyecta también, por la vía de la introducción de una nueva disposición adicional, la 20 ${ }^{\mathrm{a}}$, en la LRJ-PAC sobre todas las entidades de esta naturaleza cualquiera que sea el ámbito, estatal, autonómico o local, en el que se sitúen ${ }^{9}$. Analizamos seguidamente unas disposiciones y otras.

\subsection{La Disposición Adicional $20^{a}$ de la LRF-PAC.}

La nueva disposición adicional $20^{\mathrm{a}}$ de la LRJ-PAC, pendiente en estos momentos de pronunciamiento por el Tribunal Constitucional ${ }^{10}$, incorpora, bajo la rúbrica "ré-

9 No era así cuando se pone en marcha el proceso de modificación de la LBRL. En la primera versión de Anteproyecto de Ley que conocimos, la fechada en julio de 2012, la norma de la LRJ-PAC se introducía en el propio texto de la Ley de Régimen local. El cambio de criterio se produjo, sin embargo, muy pronto, pues ya en el siguiente borrador de Anteproyecto, de fecha 18 de febrero de 2013, se preveía la introducción de una nueva disposición adicional, la 20ª en la LRJ-PAC, opción que será definitivamente aprobada.

10 En efecto, la disposición final $2^{a}$ de la LRSAL que es la que prevé esta nueva disposición adicional de la LRJ-PAC, figura entre las normas de la Ley 27/2013 impugnadas ante el Tribunal Constitucional por el Gobierno de Cataluña que entiende que vulnera sus competencias estatutarias en materia de función pública, de autoorganización y de régimen local. Interesa señalar, no obstante, que el Dictamen 8/2014, de 
gimen jurídico de los consorcios" ${ }^{\prime 1}$, novedades significativas que pueden resumirse en los siguientes términos.

\section{A. La adscripción del consorcio.}

Esta disposición adicional prevé, ante todo, la adscripción formal del consorcio, "en cada ejercicio presupuestario y por todo este periodo", a alguna de las Administraciones Públicas que lo integran ${ }^{12}$, Administraciones sobre cuya naturaleza van a expresarse dudas, sin bien son mayoritarios los autores que consideran que ha de ser siempre una Administración territorial ${ }^{13}$. La adscripción deben determinarla los estatutos de cada entidad de conformidad con los "criterios de prioridad" que, con precedentes en algunas disposiciones anteriores ${ }^{14}$, establece el apartado $2^{\circ}$ de la disposición. De esta forma, el consorcio quedará adscrito a la Administración pública que: “a) Disponga de la mayoría de votos en los órganos de gobierno; b) Tenga facultades para nombrar o destituir a la mayoría de los miembros de los órganos ejecutivos; c)

27 de febrero, del Consejo de Garantías estatutarias de Comunidad, no apreció posible inconstitucionalidad en esta disposición al estimar que venía respaldada por las competencias del Estado en la materia.

11 Estamos ante una norma que apenas suscitó controversias durante la tramitación parlamentaria de la LRSAL. A la disposición final $2^{a}$ tan sólo se presentaron dos enmiendas que proponían su supresión, la del Grupo parlamentario socialista que se oponía a una modificación de los consorcios "teniendo en cuenta únicamente criterios economicistas y sin permitir valorar otro tipo de criterios" (enmienda número 473); y la del Grupo mixto a instancias de Geroa-Bai (enmienda número 124). Las enmiendas pueden consultarse en el Boletín Oficial de las Cortes Generales. Congreso de los Diputados, X Legislatura, Serie A, núm. 58-2, 30 de octubre de 2013.

El Grupo parlamentario socialista del Senado reiteró en esta cámara su petición (enmienda número 223), a la que se sumó entesa pel pogrés de Catalunya (enmienda número 339). Las enmiendas planteadas a la Ley en el Senado fueron publicadas en el Boletín Oficial de las Cortes Generales, Senado, núm. 276-1993, de 28 de noviembre de 2013.

${ }_{12}$ Así lo establece su apartado $1^{\circ}$ en un criterio que viene a confirmar el $3^{\circ}$ que prohíbe que el consorcio pueda adscribirse, en caso de pertenecer a el, a una entidad privada sin ánimo de lucro. Esta previsión tiene de positivo, según se ha dicho, el reconocimiento expreso por la norma "siquiera sea por vía indirecta, de la posibilidad de incorporar al consorcio entidades privadas sin ánimo de lucro", opción ya existente en la LBRL pero que "no había sido recibida como norma estatal básica para todos los consorcios administrativos por la LRJPAC" (F. TOSCANO GIL, "El consorcio administrativo en la encrucijada", REALA, nueva época, núm. 3, 2105, pág. 7. Ha de advertirse que en la cita de este trabajo se sigue la numeración del propio estudio).

13 En tal sentido, M. HERNANDO RYDINGS ("Las Mancomunidades y los Consorcios", ALMEIDA GERREDA, M, G. TUBERTINI y P. COSTA GONĢALVES (Dirs.), La racionalización de la organización administrativa local: Las experiencias española, italiana y portuguesa, Civitas-Thomson Reuters, 2015, pág. 164) y Ma.A. GONZÁLEZ BUSTOS (Capítulo 10. El nuevo reto de los consorcios", QUINTANA LÓPEZ, T., Dir., La reforma del régimen local, Tirant lo Blanch, Valencia, 2014).

14 Precedentes recogidos, tanto a nivel estatal como autonómico, por A. KONINCKX FRASQUET, "Capítulo 14. De nuevo sobre los consorcios" (M.J. DOMINGO ZABALLOS, Coor., Reforma del Régimen Local. La Ley de Racionalización y Sostenibilidad de la Administración Local: Veintitrés estudios, Thomson Reuters-Aranzadi, 2014, págs. 580-1). 
Tenga facultades para nombrar o destituir a la mayoría de los miembros del personal directivo; d) Disponga de un mayor control sobre la actividad del consorcio debido a una normativa especial; e) Tenga facultades para nombrar o destituir a la mayoría de los miembros del órgano de gobierno; f) Financie en más de un cincuenta por cien o, en su defecto, en mayor medida la actividad desarrollada por el consorcio, teniendo en cuenta tanto la aportación del fondo patrimonial como la financiación concedida cada año; g) Ostente el mayor porcentaje de participación en el fondo patrimonial; y h) Tenga mayor número de habitantes o extensión territorial dependiendo de si los fines definidos en el estatuto están orientados a la prestación de servicios, a las personas, o al desarrollo de actuaciones sobre el territorio". Prescindo aquí de la valoración de estos criterios que han sido ya objeto de análisis por diferentes autores que, aún cuando valoran positivamente su propia determinación en lo que aportan de seguridad jurídica, se han mostrado, por lo general, críticos con el afán de exhaustividad que muestra la norma que le ha llevado a la "desagregación de criterios estrechamente relacionados entre si”" ${ }^{\prime \prime}$. Tampoco faltan opiniones que ponen el acento en los problemas que pueden generar en su aplicación ${ }^{16}$ o que cuestionan, incluso, su misma constitucionalidad ${ }^{17}$. Ahora bien, lo que no parece discutible es que esta adscripción, dadas las consecuencias que, como vamos ver, implica puede suponer una drástica disminución en el número de consorcios, hasta el punto de haber sido calificada, desde una perspectiva práctica, de "nefasta para la institución consorcial"18.

15 En este sentido se expresa, en la misma línea que E. NIETO ("La Ley de Racionalización y Sostenibilidad de la Administración Local y los consorcios administrativos", op. cit., págs. 373-4 y "La reforma de las entidades instrumentales por la Ley de Racionalización y Sostenibilidad de la Administración local", Revista Española de Derecho Administrativo, núm. 165, 2014, págs. 121-122), F. TOSCANO GIL para quien esos criterios podrían, en realidad, haber quedado resumidos en los tres siguientes: "primero, el control mayoritario o efectivo de los órganos de gobierno del consorcio; segundo, la aportación económica mayoritaria al mismo; y, tercero, el mayor número de habitantes o extensión territorial" ("El consorcio administrativo en la encrucijada", op. cit., págs. 7 y 8). Una valoración de los mismos puede encontrarse también en A. KONINGKX FRASQUET (“Capítulo 14. De nuevo sobre los consorcios”, op. cit., págs.581-584).

16 Como son los casos de E. NIETO y E. MONTOYA MARTÍN que reparan en los problemas que puede suscitar, en términos de esta última autora, "el empate" entre los criterios establecidos en la norma ("Los instrumentos de colaboración pública-privada en la gestión de los servicios de interés general: El consorcio local y ¿isu racionalización?", Servicios de interés general, colaboración público-privada y sectores especificos, en prensa). Una posibilidad que E. NIETO ejemplificó en el "Consorcio Ciudad orquesta de Málaga" participado al 50\% por la Junta de Andalucía y el Ayuntamiento de esta ciudad sin que a priori sirvan los criterios legales para determinar de forma clara la adscripción a una u otra Administración. La solución a la que se ha llegado, según nos cuenta, es la adscripción por un plazo de 4 años a la Junta de Andalucía, y pasado dicho plazo, al Ayuntamiento de Málaga por igual periodo ("La reforma de las entidades instrumentales por la Ley de Racionalización y Sostenibilidad de la Administración local”, op. cit., pág. 121).

${ }_{17}$ En tal sentido, M. HERNANDO RYDINGS, "Las Mancomunidades y los Consorcios", op. cit., pág. 163.

18 E. NIETO "La Ley de Racionalización y Sostenibilidad de la Administración Local y los consorcios administrativos", op. cit., pág. 373. 
B. Las consecuencias de la adscripción. El régimen jurídico de la entidad.

La adscripción no determina el entero régimen jurídico del consorcio, toda vez que los apartados $4^{\circ}$ y $5^{\circ}$ de la disposición adicional $20^{\mathrm{a}}$ de la LRJ-PAC circunscriben sus efectos a dos ámbitos muy concretos.

De una parte, la adscripción conlleva la sumisión de la entidad "al régimen de presupuestación, contabilidad y control de la Administración pública a la que estén adscritos, sin perjuicio de su sujeción a lo previsto en la Ley Orgánica 2/2012, de 27 de abril, de Estabilidad Presupuestaria y Sostenibilidad Financiera". En todo caso, añade la norma, "se llevará a cabo una auditoria de las cuentas anuales que será responsabilidad del órgano de control de la Administración a la que se haya adscrito el consorcio" Los consorcios, además, "deberán formar parte de los presupuestos e incluirse en la cuenta general de la Administración pública de adscripción". Esta incorporación del consorcio a la cuenta general de la Administración a la que queda vinculado, lleva razonablemente a pensar que las Administraciones Públicas se retraerán a la hora de constituir unas entidades que pueden comprometerlas, con las graves consecuencias que ello comporta, en el cumplimiento de los objetivos de estabilidad presupuestaria y sostenibilidad financiera con los que han de cumplir.

La adscripción, de otra parte, deja sentir sus efectos en el ámbito del personal del consorcio, respecto del que se establece que, ya sea "laboral o funcionario", habrá de proceder "necesariamente de las Administraciones Públicas participantes" a cuyo régimen jurídico quedará sujeto, sin que sus retribuciones además "puedan superar las establecidas para puestos de trabajo equivalentes en aquélla" ${ }^{19}$. A contrario sensu, se impide que el consorcio pueda disponer de personal propio. Consciente probablemente de los inconvenientes que puede presentar una regla formulada en términos absolutos, la Ley Orgánica 6/2015, de 12 de junio ${ }^{20}$, suavizó esta prohibición con la introducción de un nuevo párrafo en el apartado $5^{\circ}$ de la disposición adicional $20^{\mathrm{a}}$ que faculta al consorcio para contratar personal propio, cuando ello sea necesario "en atención a la singularidad de las funciones a desempeñar" y así lo autorice "el Ministerio de Hacienda y Administraciones Públicas u órgano competente de la Administración a la que se adscriba el consorcio"21. Existen, no obstante, determinados consorcios al

19 La nueva "Nota explicativa del régimen local", de 29 de abril de 2016, del Ministerio de Hacienda y Administraciones Públicas ha aclarado que el personal propio de los consorcios que no proceda de ninguna de las Administraciones que lo integran "debería quedar adscrito a la Administración Pública a la que quede adscrito el consorcio de que se trate".

20 Esta Ley modifica la Ley Orgánica 8/1980, de 22 de septiembre, de Financiación de las Comunidades Autónomas y la Ley Orgánica 2/2012, de 27 de abril, de Estabilidad Presupuestaria y Sostenibilidad Financiera.

21 El Ministerio de Hacienda y Administraciones Públicas en una "Nota explicativa del régimen local" 
margen de esta prohibición: los previstos en las disposiciones adicionales $13^{\mathrm{a}}$ y $14^{\mathrm{a}}$ de la LRSAL. Esto es, los constituidos antes de su entrada en vigor que presten servicios mínimos o que reúnan los siguientes requisitos: "no tengan la consideración de Administración Pública a efectos del Sistema Europeo de Cuentas, estén participados por Entidades Locales y entidades privadas, no estén incursos en pérdidas durante dos ejercicios consecutivos y no reciban ni hayan recibido subvenciones de las Administraciones Públicas en los cinco ejercicios anteriores al de entrada en vigor de esta Ley con independencia de las aportaciones a las que estén obligados los entes consorciados", consorcios que "en tanto se mantengan todas las condiciones mencionadas", continuarán regidos "por lo previsto en sus respectivos estatutos".

Fuera de estas concretas materias, al consorcio le será aplicable lo dispuesto en sus estatutos a los que corresponde determinar, como indica el apartado $1^{\circ}$ de la propia disposición adicional $20^{\mathrm{a}}$, "su régimen orgánico, funcional y financiero de acuerdo con lo previsto en los siguientes apartados". El problema, por tanto, surgirá en los supuestos en los que los estatutos no determinen ese régimen o este sea insuficiente, ante lo que, como se ha dicho, habrá que "acudir a las normas que regulen el régimen jurídico de la Administración de adscripción para aplicárselas con carácter supletorio” como "entidad instrumental de la misma"22, opinión que cuenta, no obstante, con alguna voz discrepante ${ }^{23}$.

\section{El plazo de adaptación.}

La disposición transitoria 6 a dispuso un plazo de un año para que "los consorcios que ya estuvieran creados en el momento de la entrada en vigor de esta Ley" adaptaran sus estatutos a las nuevas exigencias legales, plazo que se ampliaba al 1 de enero

de 29 de abril de 2016 ha señalado que esta previsión debe ponerse además "en conexión con las previsiones de la Disposición Adicional décima séptima de la Ley 48/2015, de Presupuestos Generales del Estado para el año 2016, cuyo apartado Uno, permite la realización de contratos indefinidos con el límite del cincuenta por ciento de su tasa de reposición, conforme a las reglas previstas en el artículo 20. Uno, 4 de la misma. Igualmente, establece para los consorcios participados mayoritariamente por las Administraciones y organismos que integran el sector público, la posibilidad de llevar a cabo contrataciones temporales, en casos excepcionales y para cubrir necesidades urgentes e inaplazables".

${ }^{22}$ En tal sentido, E. NIETO ("La Ley de Racionalización y Sostenibilidad de la Administración Local y los consorcios administrativos", op. cit., pág. 373 y "La reforma de las entidades instrumentales por la Ley de Racionalización y Sostenibilidad de la Administración local”, op. cit., pág. 121) en una opinión que comparte A. KONINCKX FRASQUET, “Capítulo 14. De nuevo sobre los consorcios” (op. cit., págs. 582-584).

${ }^{23}$ Es el caso de F. TOSCANO que aún cuando considera que la tesis anterior "puede parecer más operativa y armoniosa", mantiene, con fundamento en el tenor literal de la norma que solo determina la sujeción del consorcio al régimen presupuestario, contable, de control, y de personal de la Administración de adscripción, la posibilidad de una segunda interpretación, la que entienda aplicable, fuera de estas concretas materias, la normativa autonómica ("El consorcio administrativo en la encrucijada", op. cit., pág. 9). 
del año siguiente, si la adaptación suponía “un cambio en el régimen jurídico aplicable al personal a su servicio o en su régimen presupuestario, contable o de control" 24 .

\subsection{Las modificaciones introducidas en los consorcios locales.}

La reforma de 2013 incide también en los consorcios locales que se ven afectados por las siguientes medidas.

A. La modificación del artículo 57 de la LBRL.

La LRSAL da nueva redacción al artículo 57 de la LBRL de tal forma que se imponen requisitos para la creación de consorcios inexistentes en la redacción originaria de la norma: mejorar la eficiencia de la gestión pública, eliminar duplicidades administrativas y cumplir con la legislación de estabilidad presupuestaria y sostenibilidad financiera ${ }^{25}$; y se les confiere un carácter subsidiario, en la medida en que, de acuerdo con el nuevo apartado $3^{\circ}$ del precepto, su constitución "solo podrá tener lugar cuando la cooperación no pueda formalizarse a través de un convenio y siempre que, en términos de eficiencia económica, aquélla permita una asignación más eficiente de los recursos económicos" ${ }^{26}$. Se limita así de forma importante la libertad de las entidades locales para la elección de la forma de cooperación que consideren adecuada, al venir obligadas a optar, con carácter general, por el convenio, pudiendo acudir al consorcio

${ }^{24}$ Sobre los problemas planteados por este régimen transitorio, me remito al estudio de E. NIETO, "La reforma de las entidades instrumentales por la Ley de Racionalización y Sostenibilidad de la Administración local” (op. cit., págs. 115-118).

25 Unos condicionamientos que ya han sido merecedores de la atención de la doctrina que destaca, por ejemplo, la indeterminación del criterio de la eficiencia administrativa frente a la mayor concreción "del objetivo de eliminar o evitar duplicidades administrativas" y respetar el principio de estabilidad presupuestaria (E. NIETO, "La Ley de Racionalización y Sostenibilidad de la Administración Local y los consorcios administrativos", op. cit., pág. 363) o pondera su valor como mecanismo para evitar "la creación artificial y no necesaria" de entes que no mejoren realmente la capacidad de gestión de los distintos servicios (L. MELLADO RUÍZ, Genésis y realidad de la Ley 27/2013, de Racionalización y Sostenibilidad de la Administración Local: ¿una nueva reforma económica local?, CEMCI, Granada, 2014, 317), de ahí que se considere que estos nuevos requisitos entran "dentro de lo razonable" (R. JIMÉNEZ ASENCIO “¿"Réquiem” por los consorcios?", Blog wrere.estudiconsultaria.com, 7 de junio de 20014, pág. 3).

26 Interesa señalar que el precepto se aprobó prácticamente en los mismos términos con los que figuraba en la primera versión del Anteproyecto de Ley que se conoció, la fechada en julio de 2012. La única diferencia relevante es la que aparece en el apartado $3^{\circ}$ que exige que se verifique que la constitución del consorcio no pondrá en riesgo la sostenibilidad financiera del conjunto del conjunto de la Hacienda local. La primera propuesta de artículo establecía que "en la constitución del consorcio se garantizará la sostenibilidad financiera de las Administraciones...", redacción que mantienen las versiones de 18 de febrero y 24 de mayo de 2013. En la de 15 de julio de ese mismo año, el precepto aparece en los términos en los que será finalmente aprobado, primero como Proyecto de Ley (Boletín Oficial de las Cortes Generales. Congreso de los Diputados, X Legislatura, Serie A, núm. 58-1, 6 de septiembre de 2013) y, más tarde, como Ley. 
solo si motivan que el convenio no es posible y que además esta opción permite "una asignación más eficiente de los recursos económicos", lo que, a juicio de M. MEDINA, "parece excesivamente reductor del margen de maniobra inherente a la potestad de autoorganización de las entidades locales" ${ }^{27}$. Este nuevo apartado del artículo 57 añade una última exigencia: "en todo caso, habrá de verificarse que la constitución del consorcio no pondrá en riesgo la sostenibilidad financiera del conjunto de la Hacienda de la Entidad Local de que se trate, así como del propio consorcio, que no podrá demandar más recursos de los inicialmente previstos".

La constitucionalidad del precepto, objeto durante su tramitación de las enmiendas de algunos Grupos parlamentarios que proponían su eliminación o, cuanto menos, su modificación sustancial ${ }^{28}$, ha sido confirmada recientemente por la Sentencia del Tribunal Constitucional 41/2016, de 3 de marzo, que resuelve el recurso de inconstitucionalidad interpuesto contra la LRSAL por la Asamblea de Extremadura. El Tribunal, como ya habían mantenido la mayoría de los órganos consultivos en los procedimientos seguidos para la impugnación de la norma ${ }^{29}$, estima que el nuevo

${ }^{27}$ La reforma del régimen local, Tirant lo Blanch, Valencia, 2014, págs. 84 y 85.

Sobre los términos en los que ha de interpretarse ese principio de preferencia puede verse A. KONINCKX FRASQUET, "Capítulo 14. De nuevo sobre los consorcios” (op. cit., págs. 567-569).

${ }^{28} \mathrm{El}$ artículo no suscitó demasiada controversia durante la tramitación parlamentaria de la Ley, aunque fue objeto de varias enmiendas en el Congreso de los Diputados. Así la formulada por el diputado J. Baldoví del Grupo mixto que proponía, con la justificación de una "mejora técnica", la supresión de los apartados $2^{\circ}$ y $3^{\circ}$ (enmienda número 56), petición de eliminación de la norma que el Grupo parlamentario vasco circunscribía, "por respeto a la autonomía local", al apartado $3^{\circ}$ (enmienda número 269). El Grupo parlamentario socialista, sin embargo, propuso la eliminación de todo el artículo al entender, según consta en la motivación de la enmienda, que "se aprecia que para la constitución de consorcios el proyecto de ley solo tiene en cuenta criterios economicistas sin permitir valorar otros criterios sobre la funcionalidad de los servicios que prestan" (enmienda número 443). Otras enmiendas pretendían no la desaparición, sino la modificación del precepto. Era el caso de la propuesta por la diputada de coalición canaria, A. Oramas, integrada en el Grupo mixto que pedía que desapareciera del apartado $3^{\circ}$ la referencia a la imposibilidad de que el consorcio pueda "demandar más recursos de los inicialmente previstos", por resultar una limitación "desproporcionada y falta de motivación” (enmienda número 159) o la del Grupo parlamentario catalán que solicitaba la modificación del apartado $2^{\circ}$ para que se excluyera de su texto la referencia a la eliminación de "duplicidades administrativas" (enmienda número 374).

Estas fuerzas políticas reiteraron, de nuevo sin éxito, sus pretensiones en el Senado como puede comprobarse en las enmiendas propuestas por los senadores de coalición canaria integrados en el Grupo mixto (enmienda número 46) o en la presentada por el Grupo parlamentario socialista (enmienda número 191). También los Grupos parlamentarios entesa pel progrés de Catalunya (enmienda número 303) y vasco (enmienda número 404) pidieron en esta cámara la supresión del artículo 57.

${ }_{29}$ Estos órganos habían mantenido, en efecto, una opinión favorable, por lo general, a la constitucionalidad de la regulación ofrecida por este artículo, de la que se rechazaba que supusiera una lesión de la autonomía constitucionalmente garantizada y se destacaba su apoyo en el principio de estabilidad presupuestaria que, tras la reforma del artículo 135 de la Constitución, constituye un "nuevo canon de constitucionalidad". Así lo estimó el Consejo de Estado en su Dictamen 33/2014, de 22 de mayo, emitido en el procedimiento relativo al planteamiento del conflicto en defensa de la autonomía local, y así lo ha 
artículo 57 de la LBRL no incluye "una regulación completa del consorcio que pudiera desbordar la competencia estatal para fijar las bases del régimen local. Introduce solo algunos límites a la constitución y funcionamiento del consorcio que, con independencia de su eficacia real, están claramente destinados a introducir los criterios de racionalidad económica que exige la realización de mandatos constitucionales". Concretamente, "la preferencia asignada a la fórmula convencional en detrimento de la consorcial (apartado 3) puede discutirse políticamente, pero constituye una directriz directamente encaminada a desarrollar una política de contención de personificaciones públicas que se sitúa dentro de los amplios márgenes de configuración legislativa que abre la Constitución y amparan los apartados 14 y 18 del art. 149.1 CE.”.

B. La incidencia en los consorcios de las medidas de "redimensionamiento del sector público local” de la disposición adicional 9a de la LBRL.

No es cometido de este trabajo el análisis exhaustivo del contenido y problemas interpretativos suscitados por la nueva disposición adicional $9^{a}$ de la LBRL. Tampoco es este el lugar propicio para su valoración ${ }^{30}$. A los efectos que nos interesan, es suficiente con destacar que las medidas de "redimensionamiento del sector público local" incorporadas por esta norma afectan de manera importante a los consorcios. Así, y en síntesis:

- Se prohíbe a las entidades locales y organismos autónomos dependientes de ellas "constituir o participar en la constitución" de un consorcio durante el tiempo de vigencia de un plan económico-financiero o un plan de ajuste.

- Se impone a los consorcios que a la entrada en vigor de la Ley se encuentre "en desequilibrio financiero", la obligación de aprobar un plan de corrección de dicho desequilibrio en el plazo de dos meses" con riesgo, en caso contrario, de disolución de la entidad ${ }^{31}$.

entendido también el Consejo de Navarra en su Dictamen 13/2014, de 12 de mayo, en una posición de la que se separa, sin embargo, parcialmente el Consejo de Garantías estatutarias de Cataluña que en su Dictamen 8/2014, de 27 de febrero, sí considera que el reformado artículo 57.3 de la LBRL "constituye una limitación drástica y desmesurada" de la posibilidad de crear consorcios que "contraviene el derecho de los municipios a cooperar entre sí y con otros entes públicos para ejercer sus competencias y realizar tareas de interés común, lo que, entre otros aspectos, se manifiesta en la capacidad de crear consorcios, tal como dispone el artículo 87.2 EAC y recoge, en un mismo sentido, el artículo 10.1 de la Carta Europea de Autonomía Local".

${ }^{30}$ Me remito al efecto al estudio de E. MONTOYA MARTÍN, "Medidas de redimensionamiento del sector público instrumental local antes y después de la Ley 27/2013, de 27 de diciembre de Racionalización y Sostenibilidad de la Administración local", Revista General de Derecho Administrativo, núm. 36, 2014.

$31 \mathrm{El}$ apartado $2^{\circ}$ de la disposición dispone que "a estos efectos, la entidad local de la que dependa "podrá realizar aportaciones patrimoniales o suscribir ampliaciones de capital de sus entidades solo si, en 
- Finalmente se les impide que puedan "constituir, participar en la constitución" o "adquirir nuevos entes de cualquier tipología". En otros términos, se prohíben las denominadas entidades instrumentales en cascada o de segundo grado o nivel. Con esta limitación, los consorcios ya no podrán, pues, optar, para la prestación de sus servicios, por la creación de una entidad instrumental, no obstante lo dispuesto en el artículo 110.5 del TRRL que le permite utilizar cualquiera de los modos de gestión previstos en la legislación de régimen local ${ }^{32}$. Respecto de las entidades de este tipo existentes a la entrada en vigor de la Ley, el apartado $4^{\circ}$ de esta disposición las diferencia, a los efectos de su adscripción directa a la entidad local o su disolución, según estén o no controladas exclusivamente por entidades vinculadas o dependientes de una entidad local territorial ${ }^{33} \mathrm{y}^{34}$.

\section{Otras disposiciones de la LRSAL con repercusión en los consorcios.}

Junto a las señaladas, existen también otras previsiones legales que dejan sentir sus efectos en el ámbito del consorcio. Así las relativas a la masa salarial del personal laboral del sector público establecidas en el nuevo artículo 103 bis) de la LBRL o a la prohibición de disponer de personal eventual resultante del artículo 104.bis). Los consorcios, en su condición de entidad perteneciente al sector público, están igualmente

el ejercicio presupuestario inmediato anterior, esa entidad Local hubiere cumplido con los objetivos de estabilidad presupuestaria y deuda pública y su período medio de pago a proveedores no supere en más de treinta días el plazo máximo previsto en la normativa de morosidad". Si "esta corrección no se cumpliera a 31 diciembre de 2014, la Entidad Local en el plazo máximo de los seis meses siguientes a contar desde la aprobación de las cuentas anuales o de la liquidación del presupuesto del ejercicio 2014 de la entidad, según proceda, disolverá cada una de las entidades que continúe en situación de desequilibrio. De no hacerlo, dichas entidades quedarán automáticamente disueltas el 1 de diciembre de 2015”. Estos plazos se amplían "hasta el 31 de diciembre de 2015 y el 1 de diciembre de 2016, respectivamente, cuando las entidades en desequilibrio estén prestando" alguno de los siguientes servicios: "abastecimiento domiciliario y depuración de aguas, recogida, tratamiento y aprovechamiento de residuos, y transporte público de viajeros".

32 En tal sentido. F. TOSCANO GIL, "El consorcio administrativo en la encrucijada”, op. cit., pág. 13. El precepto, al igual que el 40 del Reglamento de Servicios de las Corporaciones Locales es derogado por la disposición derogatoria única (letras b) y h) de la LRJSP.

33 Para las primeras, siempre y cuando no estuvieran "en situación de superávit", se disponía que en el plazo de tres meses, desde la entrada en vigor de la Ley, tendrían que adscribirse o vincularse directamente a la entidad local o disolverse, iniciando "el proceso de liquidación en el plazo de tres meses a contar desde la fecha de disolución. De no hacerlo, dichas entidades quedarán automáticamente disueltas, añadía la norma, transcurridos seis meses desde la entrada en vigor de esta Ley". Para las segundas se disponía que, en un plazo igualmente de tres meses, deberían "proceder a la transmisión de su participación". Estos plazos se amplían en un año más, "cuando las entidades en desequilibrio estén prestando alguno de los siguientes servicios esenciales: abastecimiento domiciliario y depuración de aguas, recogida, tratamiento y aprovechamiento de residuos, y transporte público de viajeros".

34 Sobre el alcance de las medidas establecidas en la disposición adicional 9a de la LBRL y las dudas que suscita en su aplicación, me remito a la "Nota explicativa del régimen local", la segunda de las dictadas, emitida por el Ministerio de Hacienda y Administraciones Públicas de 29 de abril de 2016. 
afectados por las limitaciones impuestas por la disposición adicional $12^{\mathrm{a}}$ en cuanto al número de directivos y miembros de los órganos de gobierno de la entidad.

\subsection{Consideración final.}

En definitiva, con la LRSAL se opera en nuestro ordenamiento una modificación sustancial del régimen de los consorcios en general, y especialmente, de los locales. Una reforma que se traduce en una ampliación considerable del Derecho estatal básico que viene a limitar las posibilidades normativas con las que, hasta ese momento, parecía contar el legislador autonómico en la regulación de la figura y que viene igualmente a constreñir el amplio margen de actuación del que disponían las propias Administraciones Públicas a la hora de constituir consorcios y definir en los estatutos su régimen jurídico propio. Quizás, y como ha destacado E. NIETO, "desde un punto de vista dogmático doctrinal, la institución del consorcio administrativo resulta favorecida por la reforma porque clarifica su régimen jurídico propio", aunque "desde un punto de vista práctico, probablemente con la reforma desaparecerán numerosos consorcios y, además, es posible que la institución consorcial no se utilice en el futuro con tanta frecuencia como en la actualidad" 35 . De otra parte, y con sus previsiones sobre la adscripción del consorcio, la reforma legal de 2013 acentúa su consideración de ente instrumental frente a su tradicional dimensión asociativa que, sin desaparecer, queda, desde luego, más diluida ${ }^{36}$. El Ministerio de Hacienda y Administraciones Públicas en su "Nota explicativa del régimen local" de 29 de abril de 2016 ha afirmado que con la disposición adicional $20^{\mathrm{a}}$ de la LRJ-PAC "queda clarificada la naturaleza jurídica de los consorcios" que son "configurados como entidades instrumentales de cooperación interadministrativa adscritas a alguna de ellas", lo que impide que "un consorcio local en la medida en que resulta adscrito a una Administración Local", pueda "gozar de la naturaleza de Entidad Local cuyo régimen jurídico no es el propio de un ente instrumental".

\section{La Ley 15/2014, de reforma del sector público. La confirmación del camino iniciado.}

Cuando se promulga la LRSAL está ya tramitándose en las Cortes Generales la que será aprobada como Ley 15/2014, de 16 de septiembre, de Racionalización del Sector público y otras medidas de reforma administrativa. Esta norma, inserta igual-

\footnotetext{
35 "La reforma de las entidades instrumentales por la Ley de Racionalización y Sostenibilidad de la Administración local", op. cit., págs. 112-113.

36 En tal sentido, R. JIMÉNEZ ASENCIO (“¿"Réquiem” por los consorcios?”, op. cit., pág. 2) y F. TOSGANO GIL ("El consorcio administrativo en la encrucijada", op. cit, pág. 7).
} 
mente en el proceso de racionalización de las estructuras administrativas impuesto por los principios de estabilidad presupuestaria y sostenibilidad financiera, manifiesta en su Preámbulo la voluntad legal de introducir "un régimen jurídico, con carácter básico, sencillo y ex novo del derecho de separación de los miembros del consorcio administrativo y, cuando ello dé lugar a su disolución", de "las reglas por las que se regirá”. Una normativa provisional, añade, en espera de que en la futura Ley de Régimen Jurídico de las Administraciones Públicas se incluya un régimen "integral y básico" referido a los consorcios, que derogaría esta regulación, así como la prevista en la LRSAL. De esta forma, el legislador estatal vuelve, de nuevo con carácter básico ${ }^{37}$, a incidir en el régimen de los consorcios completando la regulación establecida, pocos meses antes, por la Ley 27/2013, con lo que, como advirtió el Consejo de Estado en su Dictamen 1221/2013, de 12 de diciembre, al Anteproyecto de Ley, da "un paso adicional en la dispersión normativa existente en la materia". No debe de pasar desapercibido, de otra parte, que, como destaca E. NIETO, esta disposición se proyecta sobre materias objeto, en algunos casos, de regulación por el ordenamiento autonómico ${ }^{38}$. Una regulación que, a partir de ahora, solo será aplicable en cuanto no contradiga el nuevo Derecho básico estatal.

Las nuevas disposiciones sobre los consorcios, calificadas por el órgano consultivo del Estado en ese mismo dictamen, como "uno de los aspectos que mayor protagonismo reviste en el anteproyecto" y que fueron ampliamente cuestionadas durante su tramitación parlamentaria ${ }^{39}$, abordan, como se ha apuntado, dos extremos muy concretos del régimen de la entidad aunque de gran trascendencia: el derecho de separación de los miembros del consorcio y su liquidación en los términos que seguidamente se exponen.

37 Como establece la disposición final $4^{\mathrm{a}}$.

38 Son los supuestos, citados por la propia autora, del Decreto de Cataluña 179/1995, de 13 de junio, por el que se aprueba el Reglamento de obras, actividades y servicios de las Entidades locales o de la Ley

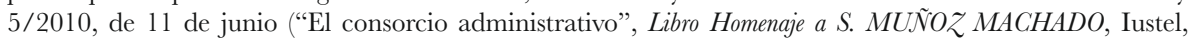
Madrid, en prensa, págs. 2114 y 2115).

39 Así el Grupo parlamentario socialista presentó enmiendas tanto en el Congreso de los Diputados como en el Senado en las que solicitaba la supresión de una regulación que consideraba "del todo inapropiada (enmiendas números 129 a 132 y 130 a 133, respectivamente). También la diputada Jordá i Roura, integrada en el Grupo mixto del Congreso, formuló enmiendas en las que solicitaba la desaparición del conjunto de preceptos que el Proyecto de Ley dedicaba a los consorcios (enmiendas número 111 a 114), al igual que lo hizo en el Senado el Grupo parlamentario entesa pel progrés de Catalunya (enmiendas números 61 a 64$)$. 


\subsection{El derecho de separación de los miembros del consorcio}

El artículo 12 de la Ley regula "las causas y procedimiento para el ejercicio del derecho de separación de un consorcio" ${ }^{40}$.

Las causas, en primer lugar, se establecen en función de si el consorcio tiene o no prevista una duración determinada. En caso de no tenerla, los miembros de la entidad, "podrán separarse del mismo en cualquier momento". Si, por el contrario, dispone de ella, "cualquiera de sus miembros podrá separarse antes de la finalización del plazo determinado" si algún otro "hubiera incumplido alguna de sus obligaciones estatutarias y, en particular, aquellas que impidan cumplir con el fin para el que fue creado el consorcio, como es la obligación de realizar aportaciones al fondo patrimonial" ${ }^{41}$. Junto a esta, se prevé una segunda causa de separación, la que se reconoce al Municipio que "deje de prestar un servicio, de acuerdo con lo previsto en la Ley 27/2013, de 27 de diciembre, de racionalización y sostenibilidad de la Administración Local" para el caso de que dicho "servicio sea uno de los prestados por el Consorcio al que pertenece". Cabe notar la imprecisión de la norma en "la utilización del término servicio", ante lo que se ha propuesto una interpretación que entienda que "el legislador se está refiriendo a competencias municipales que, tras la LRSAL, dejen de serlo, como las competencias distintas de las propias o de las atribuidas por delegación, a las que se refiere el artículo 7.4 LBRL, o algunas de las que salen de la órbita municipal y pasan a la Comunidad Autónoma, con la nueva redacción del art. 25.2 LBRL"42.

40 Un regulación aplicable, como establece el apartado $1^{\circ}$ del precepto, a los consorcios a los "que le resulte de aplicación lo previsto en la Ley 30/1992, de 26 de noviembre, de Régimen Jurídico de las Administraciones Públicas y del Procedimiento Administrativo Común o en la Ley 7/1985, de 2 de abril, reguladora de las Bases del Régimen Local"; esto es, a todos los consorcios administrativos.

41 El Grupo parlamentario catalán presentó una enmienda en el Congreso de los Diputados en la que solicitaba la modificación de este precepto al objeto de que el derecho de separación, en los casos en los que el consorcio se hubiera constituido por un tiempo determinado, quedara circunscrito a los supuestos en los que algún otro miembro de la entidad "hubiera incumplido gravemente alguna de sus obligaciones estatutarias". No parece de recibo, afirmaba en su justificación, que "cualquier miembro pueda separarse del mismo, con las graves consecuencias que ello puede conllevar, alegando simplemente que otros miembros no han cumplido cualquiera de sus obligaciones...". Igualmente proponía que la norma aclarase que "cuando la no aportación dineraria por parte de uno de los integrantes pueda ser causa de inviabilidad del consorcio o dificulte gravemente su actividad, las Administraciones deberán priorizar la conveniencia de mantener los compromisos económicos adquiridos, a los efectos de garantizar la continuidad del consorcio cuando sus actividades sean consideradas de interés general" (enmienda núm. 71). Las enmiendas a esta Ley se encuentran publicadas en el Boletín Oficial de las Cortes Generales. Congreso de los Diputados, Serie A, núm. 79-2, 7 de mayo de 2014.

${ }^{42}$ F. TOSCANO GIL, "El consorcio administrativo en la encrucijada", op. cit., pág. 19. 
Ahora bien, si no atenemos a la justificación de la enmienda presentada por el Grupo parlamentario popular en el Senado, en la que la previsión legal tiene su origen, parece que el precepto está previsto para "clarificar como proceder en la sustitución de la prestación de servicios de municipios afectados por la redacción de los artículos 26 y 36 de la LRBRL entre municipios y diputaciones, cuando estaban siendo prestados mediante un consorcio y el municipio decide dejar de prestarlo por no tener carácter obligatorio" ${ }^{43}$; esto es, circunscribe su aplicación al ámbito de estos artículos ${ }^{44}$.

El derecho de separación se ha de ejercer "mediante escrito notificado al máximo órgano de gobierno del consorcio" en el que ha de constar "el incumplimiento que motiva la separación, la formulación de requerimiento previo de su cumplimiento y el transcurso del plazo otorgado para cumplir tras el requerimiento"45. Aunque la expresión puede prestarse a equívocos, cabe entender que "el máximo órgano de gobierno del consorcio" será aquel en el que estén representados todos sus miembros. De otra parte, debe interpretarse, como señala E. NIETO, que esta cláusula solo es aplicable cuando se trate de separarse de consorcios de duración determinada, al ser estos los casos en los que la ley exige el previo incumplimiento de algún miembro, dado que "no es lógico considerar aplicable el citado precepto legal y obligar a justificar el ejercicio del derecho de separación en el incumplimiento de alguna obligación estatutaria de otro miembro del consorcio" cuando el derecho de separación se reconoce "de forma general en los consorcios de duración indefinida" ${ }^{46}$.

El simple ejercicio del derecho de separación produce, como determina el artículo 13.1, "la disolución del consorcio salvo que el resto de sus miembros, de conformidad con lo previsto en sus estatutos, acuerden su continuidad y sigan permaneciendo en el consorcio, al menos, dos Administraciones, o dos entidades u organismos públicos vin-

43 Enmienda número 167. Las enmiendas presentadas en esta cámara fueron publicadas en el Boletín Oficial de las Cortes Generales. Senado, núm. 365, de 12 de junio de 2014.

44 E. NIETO ha señalado que se trata de "una regulación que podía habérsela ahorrado el legislador porque resulta obvio el escaso o nulo interés que tendrá el municipio en seguir formando parte de una entidad instrumental con fines ajenos a los intereses municipales" ("El consorcio administrativo", op. cit., págs. 2116 y 2117$)$.

${ }^{45}$ El Grupo parlamentario catalán presentó una enmienda al precepto en el Congreso de los Diputados en la que pedía su desarrollo. Concretamente que se estableciera que en dicho escrito había de detallarse "el incumplimiento alegado y se requiriera su enmienda", debiendo comunicarse "asimismo al máximo órgano de gobierno del consorcio, indicando la voluntad de separarse si el requerimiento formulado no es atendido en un plazo de tres meses desde su formalización" (enmienda número 71), enmienda que reiteró en el Senado (enmienda número 38).

46 "El consorcio administrativo", op. cit., pág. 2117. 
culados o dependientes de más de una Administración" ${ }^{47}$. A sensu contrario, se excluye la posibilidad de que se mantengan consorcios formados por entidades instrumentales que dependan de una misma Administración o que puedan venir, incluso, integrados por una entidad pública y otra privada sin ánimo de lucro.

Acordada la continuidad de la entidad, habrá que proceder al cálculo de la cuota de separación que corresponda al miembro que ejercita el derecho, lo que se hará, como establece el artículo 13.2, "de acuerdo con la participación que a ese miembro que se separa le hubiera correspondido en el saldo resultante del patrimonio neto, de haber tenido lugar la liquidación, teniendo en cuenta que el criterio de reparto será el dispuesto en los Estatutos". A falta de previsión estatutaria, "se considerará cuota de separación la que le hubiera correspondido en la liquidación". En defecto de determinación de la cuota de liquidación, "se tendrán en cuenta, tanto el porcentaje de las aportaciones que haya efectuado quien ejerce el derecho de separación al fondo patrimonial del consorcio, como la financiación concedida cada año. Si el miembro del consorcio que se separa no hubiere realizado aportaciones por no estar obligado a ello, el criterio de reparto será la participación en los ingresos que, en su caso, hubiera recibido durante el tiempo que ha pertenecido al consorcio". Fijada la cuota, se acordará por la entidad "la forma y condiciones en que tendrá lugar el pago", en el caso de que sea positiva o, si es negativa, "la forma y condiciones del pago de la deuda que corresponda a quien ejerce el derecho de separación".

La efectiva separación del consorcio depende de que la cuota de separación sea positiva o negativa. En el primer caso, se producirá con su simple determinación. En el segundo, una vez que esta se haya pagado $^{48}$. Si quien se separa es la Administración de adscripción, el consorcio deberá determinar, de acuerdo con lo establecido en la disposición adicional 20a de la LRJ-PAC, la nueva Administración a la que se adscribe.

47 El Grupo parlamentario catalán en el Congreso presentó igualmente una enmienda a este precepto en la que solicitaba que la separación no produjera por si misma la disolución del consorcio, sino que tal resultado quedará relegado a lo que las partes pudieran disponer (enmienda número 72).

48 Hay que notar, en el sentido ya señalado por E. NIETO, que el legislador estatal, lo que no ha hecho, "podía haber regulado el derecho de separación" bajo "la condición de que el miembro que interese la separación estuviese al corriente de sus obligaciones con la entidad consorcial"; a cambio, ha establecido que "la separación solo será efectiva cuando, caso de ser la cuota negativa, se haya pagado la deuda" ("El consorcio administrativo", op. cit., págs. 2116-2117). 


\subsection{La liquidación del consorcio}

La disolución del consorcio produce, como determina el artículo 14.1, "su liquidación y extinción", a lo que se añade que, "en todo caso será causa de disolución que los fines estatutarios del consorcio hayan sido cumplidos". Se trata de dos reglas que pueden parecer obvias pero que quizás tengan el valor de expresar el deseo legal de corregir una realidad en la que, con frecuencia, perduran consorcios que ya han cumplido con sus fines o que, habiéndose disuelto, no se han liquidado.

La regulación legal en esta materia se centra fundamentalmente en el cálculo y pago de la cuota de liquidación. Se dispone así que "el máximo órgano de gobierno del consorcio al adoptar el acuerdo de disolución nombrará un liquidador". A falta de acuerdo, lo "será el administrador del consorcio"49. Este liquidador calculará la cuota de liquidación que "corresponda a cada miembro del consorcio de conformidad con lo previsto en los estatutos. Si no estuviera previsto en los estatutos, se calculará la mencionada cuota de acuerdo con la participación que le corresponda en el saldo resultante del patrimonio neto tras la liquidación, teniendo en cuenta que el criterio de reparto será el dispuesto en los Estatutos". A falta de previsión estatutaria, "se tendrán en cuenta tanto el porcentaje de las aportaciones que haya efectuado cada miembro del consorcio al fondo patrimonial del mismo, como la financiación concedida cada año. Si alguno de los miembros del consorcio no hubiere realizado aportaciones por no estar obligado a ello, el criterio de reparto será la participación en los ingresos que, en su caso, hubiera recibido durante el tiempo que ha pertenecido en el consorcio".

Determinada la cuota, se acordará por el consorcio "la forma y condiciones" en que tendrá lugar el pago en el supuesto de que sea positiva. Las entidades consorciadas "podrán acordar, con la mayoría que se establezca en los estatutos, o a falta de previsión estatutaria por unanimidad, la cesión global de activos y pasivos a otra entidad jurídicamente adecuada con la finalidad de mantener la continuidad de la actividad y alcanzar los objetivos del consorcio que se liquida" ${ }^{50}$.

49 F. TOSCANO manifiesta que la expresión "administrador del consorcio" podría comprender "al gerente del mismo, aunque lo cierto es que el precepto no se expresa con toda la precisión que sería deseable" ("El consorcio administrativo en la encrucijada", op. cit., pág. 20).

50 Este apartado $5^{\circ}$ del artículo 14 tiene su origen en la enmienda presentada en el Congreso de los Diputados por el Grupo parlamentario catalán que la justificaba en el hecho de que "los consorcios deben poder disponer la continuidad de su actividad siempre que se considere conveniente, por una tercera entidad, sin perjuicio de la disolución de los mismos" (enmienda número 74).

La previsión ha sido alabada por E. NIETO que entiende que "viene a dar seguridad jurídica a una práctica, la sucesión de otra entidad en la actividad del consorcio que, a falta de previsión estatutaria o disposición autonómica expresa se resolvía aplicando por analogía la regulación, entre otros, del artículo 44 del Estatuto de los Trabajadores, sobre la sucesión de empresas en cuanto al personal laboral del consorcio 


\subsection{Plazo de adaptación de los estatutos y Derecho supletorio}

Estas dos cuestiones constituyen la rúbrica del artículo 15 de la Ley que dedica, a la primera, sus apartados, $1^{\circ}$ y $2^{\circ}$; y a la segunda, el $3^{\circ}$.

Los estatutos de los consorcios que se constituyan a partir de la entrada en vigor de la Ley, han de recoger las normas sobre el derecho de separación, disolución y liquidación de la entidad que la propia Ley establece, pudiendo desarrollarlas siempre que no contravengan lo en ella dispuesto. Las entidades ya creadas, "deberán adaptar sus estatutos a lo en ella previsto en el plazo de seis meses desde su entrada en vigor". Este nuevo plazo de adaptación vino así a sumarse a los ya establecidos en la LRSAL para la adecuación de los estatutos a sus propias previsiones.

El artículo 15.3 establece finalmente la norma aplicable con carácter supletorio en los siguientes términos: "En lo no previsto en los Estatutos ni en esta Ley, se estará a lo previsto en el Código Civil sobre la sociedad civil, salvo el régimen de liquidación, que se someterá a lo dispuesto en el Real Decreto Legislativo 1/2010, de 2 de julio, por el que se aprueba el Texto Refundido de la Ley de Sociedades de Capital”. F. TOSCANO, en una interpretación de esta disposición de la que parece participar también E. NIETO ${ }^{51}$, mantiene que "pese a la dicción de este precepto legal, si no se quieren vulnerar competencias autonómicas, habrá que entender que esta supletoriedad solo juega para los consorcios estatales, o que, tratándose de consorcios administrativos con regulación en la legislación autonómica, debe pasar antes también por la posible aplicación de la misma"52.

\subsection{Valoración final}

Esta Ley avanza, sin duda, en el camino iniciado por la LRSAL, en el de una mayor regulación de la entidad por el Derecho básico estatal que redunda, de nuevo, en esa pérdida de flexibilidad que ha caracterizado tradicionalmente a la institución consorcial. Con independencia de las valoraciones que puedan hacerse, es un hecho que el número de entidades del sector público, entre ellas los consorcios, se ha reducido de

en disolución, o bien por aplicación analógica del artículo 39 Cc, que en función del carácter público de la persona jurídica en disolución dispone que los bienes se destinen a la realización de fines análogos en interés de la región, provincia o municipio" ("El consorcio administrativo", op. cit., págs. 2020-2021).

51 "El consorcio administrativo", op. cit., pág. 2119.

52 "El consorcio administrativo en la encrucijada", op. cit., pág. 19. 
forma importante en los últimos años como resulta de los propios datos que ofrece el "Informe trimestral de seguimiento de las medidas de la Comisión para la Reforma de las Administraciones Públicas" de la "oficina para la ejecución de la reforma de la Administración" $" 53$.

Esta Ley había además anunciado en su Preámbulo que sería la futura Ley reguladora del régimen jurídico de las Administraciones Públicas la encargada de establecer "un régimen integral y básico referido a los consorcios", Ley que llega el 1 de octubre de 2015 cuando en sustitución de la LRJ-PAC se aprueban dos nuevas disposiciones, las Leyes 39 y 40/2015, del Procedimiento Administrativo común de las Administraciones Públicas y Régimen jurídico del sector público, respectivamente.

\section{EL PUNTO FINAL, HASTA AHORA: LA LEY 40/2015 DE RÉGIMENJURÍDICO DEL SECTOR PÚBLICO}

La LRJSP ofrece en el Capítulo VI del Título II, declarado básico salvo en alguna de sus disposiciones ${ }^{54}$, un régimen jurídico sobre los consorcios que, en expresión tomada del Dictamen del Consejo de Estado 274/2015, de 29 de abril, al Anteproyecto de Ley, "refunde" lo ya establecido en las anteriores Leyes 27/2013 y 15/2014. En efecto, la nueva Ley, contra la que igualmente se alzaron voces críticas durante su tramitación parlamentaria ${ }^{55}$, no regula ex novo la institución; se limita a trasladar a su ámbito cuanto ha establecido ya el ordenamiento anterior, aún cuando introduce algunas innovaciones de interés en las que centraré mi atención. No obstante, y con carácter previo, debe insistirse en que nos encontramos ante una disposición que vincula a todos los consorcios, cualquiera que sea el ámbito: estatal, autonómico o local en el que se sitúen, y cuya aplicación se ha de producir desde el momento mismo de la entrada en vigor de la Ley, el próximo 2 de octubre de $2016^{56}$, toda vez que, a

${ }^{53}$ Señala concretamente que, entre 2005 y 2011, se han suprimido "un total de 2305 entidades: 115 en el estado, 754 en las CC.AA. y 1436 en las Corporaciones Locales, ello nos lleva a cifras de 2003, previas a la crisis".

54 Disposición final $14^{\mathrm{a}}$, apartado 2, letra c). De este carácter básico solo se excluye la previsión contenida en el artículo 123.2.

${ }_{55}$ Es el caso señalado del Grupo parlamentario la izquierda plural que planteó una enmienda en la que solicitaba la supresión de esta regulación al entender que "bajo el paraguas del informe de la Comisión para la reforma de las Administraciones Públicas y los objetivos de reformar y racionalizar la Administración, lo que pretende este Proyecto de Ley es una auténtica recentralización, sustentado en una extensión de las bases del régimen jurídico de las Administraciones Públicas en numerosas materias a lo largo del articulado ..." (enmienda núm. 105). Las enmiendas presentadas al Proyecto de Ley en el Congreso están publicadas en el Boletín Oficial de las Cortes Generales. Congreso de los Diputados, Serie A, núm. 154-2, 28 de julio de 2015 .

56 Disposición final $18^{\mathrm{a}}$, apartado $1^{\circ}$. 
diferencia de disposiciones anteriores, esta Ley no prevé plazos de adaptación de las entidades existentes a la nueva normativa establecida ${ }^{57}$.

\section{Algunas notas sobre la configuración de la entidad}

El artículo 118.1, con el que se inicia la regulación en la materia, ofrece, lo que debe considerarse positivo, una definición del consorcio. Son, dice, "entidades de derecho público, con personalidad jurídica propia y diferenciada, creadas por varias Administraciones Públicas o entidades integrantes del sector público institucional, entre sí o con participación de entidades privadas, para el desarrollo de actividades de interés común a todas ellas dentro del ámbito de sus competencias”. Con esta definición se consolida la consideración del consorcio como ente institucional frente a esas concepciones más tradicionales que situaban el centro de gravedad en su condición de ente asociativo.

La Ley además, en el apartado $2^{\circ}$ de este mismo precepto, concreta el objeto de la entidad, de tal forma que frente a esa expresión tradicional que lo adscribe al "desarrollo de actividades de interés común" ${ }^{58}$, establece, en términos que recuerdan mucho, por cierto, a los establecidos para los organismos autónomos en el artículo 98 de la propia Ley, que "los consorcios podrán realizar actividades de fomento, prestacionales o de gestión común de servicios públicos y cuantas otras estén previstas en las leyes". No obstante, puede seguir manteniéndose que estamos ante una fórmula suficientemente abierta que permite albergar en su ámbito lo más variados fines.

Ahora bien, la verdadera aportación de este precepto al régimen existente es la que afecta a su composición subjetiva, en donde, de una parte, queda explícitamente reconocida, y por consiguiente perfectamente clara, la posibilidad de que cualquier entidad del sector público institucional pueda, no solo, formar parte de un consorcio,

57 Es más, su disposición transitoria $2^{\mathrm{a}}$, apartado $2^{\circ}$ b) establece que las normas de la Ley se aplicarán a los consorcios estatales existentes desde el momento de la entrada en vigor de la Ley "en tanto no resulte contrario a su normativa específica", excluyendo así, respecto de estas entidades, la regla establecida con carácter general en su apartado $1^{\circ}$, en cuya aplicación "todos los organismos y entidades integrantes del sector público estatal en el momento de la entrada en vigor de esta Ley continuarán rigiéndose por su normativa específica, incluida la normativa presupuestaria que les resultaba de aplicación, hasta su adaptación a lo dispuesto en la Ley de acuerdo con lo previsto en la disposición adicional cuarta", disposición que prevé un plazo de adaptación de tres años a contar desde el momento de la entrada en vigor.

La LRJSP solo excluye de su aplicación inmediata a "los consorcios creados por una ley singular aprobada por las Cortes Generales con anterioridad a la aprobación de esta Ley" que, según establece la disposición final $17^{\mathrm{a}}$, apartado $2^{\circ}$, "seguirán rigiéndose por su legislación especial hasta que se produzca la citada adaptación normativa".

58 Artículo 87 de la LBRL. 
sino también crearlo, sin perjuicio de las limitaciones que en el ámbito local puedan resultar la disposición adicional $9^{\mathrm{a}}$ de la LBRL. De otra, se establece con carácter general la posible pertenencia a un consorcio de entidades privadas, hasta ahora prevista solo en el ámbito local, aunque se prohíbe, artículo 120.3, que pueda quedar adscrito a una entidad de esta naturaleza. Además, y a diferencia de lo establecido en el artículo 87 de la LBRL, ya no se exige que la entidad en cuestión carezca de ánimo de lucro, requisito que sin embargo, y por disposición del propio artículo 120.3, habrá de concurrir en el propio consorcio ${ }^{59}$. Es un cambio importante que abre el consorcio a las empresas privadas, lo que no deja de suscitar dudas, ya apuntadas por algunos autores, acerca, sobre todo, de cómo seleccionar a ese sujeto privado sin que se vulneren los principios de igualdad, publicidad y libre concurrencia que rigen en las fórmulas de colaboración público/privada ${ }^{60}$.

El artículo 118 prevé finalmente dos reglas de interés. La que en su apartado $3^{\circ}$ reconoce a todas las Administraciones Públicas la posibilidad, solo permitida hasta ahora a las entidades locales por el artículo 87 de la LBRL, de utilizar los consorcios para la "cooperación transfronteriza" de acuerdo "con las previsiones de los convenios internacionales ratificados por España en la materia”. Y la que exige, apartado $4^{\circ}$, que en la denominación de los consorcios figure la indicación "consorcio" o su abreviatura " $\mathrm{C}$ ", y así conste además en el inventario general de entidades del sector público estatal, autonómico y local, regulado en los artículos 82 y 83 de la propia Ley ${ }^{61}$. Todos los

59 El Grupo parlamentario vasco planteó enmiendas tanto en el Congreso (enmienda núm. 49) como en el Senado (enmienda número 154) en las que propugnaba la reforma del artículo 120.3 a fin de suprimir la previsión que establece que el consorcio, en el caso de participar entidades privadas, no tendrá ánimo de lucro.

Desde el ámbito doctrinal, E. NIETO ha destacado que la previsión del artículo 120.3 que dispone que en el supuesto de que participen en el consorcio entidades privadas, este no tendrá ánimo de lucro, "suscita la pregunta de si los demás consorcios pueden tener ánimo de lucro". En su opinión, "los consorcios administrativos no estaban concebidos como entidades con ánimo de lucro, sino que tenían por finalidad satisfacer intereses públicos, de ahí que cuando participaban entidades privadas se exigía que no tuviesen ánimo de lucro, sino intereses concurrentes con los de las Administraciones públicas (art. 87.1 LBRL). Parece ser que la nueva regulación del consorcio está pensando en otro tipo de entidad" "Los consorcios administrativos", op. cit., pág. 2126).

${ }^{60}$ En particular, por F. GARCÍA RUBIO a cuyas reflexiones sobre las posibilidades que se abren en este sentido y los problemas que se suscitan, me remito (Los consorcios locales en el Proyecto de Ley de Régimen jurídico del sector público. Reflexiones necesarias”, Documentación Administrativa, núm. 2, 2015).

${ }^{61}$ El Grupo parlamentario catalán propuso en el Congreso la supresión de este apartado $4^{\circ}$ del precepto al estimar que "elementos tan detallados" no parecen procedentes en "las bases del régimen jurídico de las Administraciones Públicas" (enmienda número 131), propuesta que volvió a formular en el Senado (enmienda número 66). 
consorcios existentes en el momento de la entrada en vigor de la Ley "deberán estar inscritos en el Inventario de Entidades del Sector Público Estatal, Autonómico y Local en el plazo de tres meses" a contar desde esa fecha, en cumplimiento de lo dispuesto en la disposición adicional octava.

\section{El sistema de fuentes}

El artículo 119 determina el régimen jurídico aplicable al consorcio. Se regirán por "lo establecido en esta Ley, en la normativa autonómica de desarrollo y sus estatutos". En lo no previsto en este conjunto normativo, y en relación concretamente con el "derecho de separación, disolución, liquidación y extinción, se estará a lo previsto en el Código Civil sobre la sociedad civil, salvo el régimen de liquidación, que se someterá a lo dispuesto en el artículo 97, y en su defecto, el Real Decreto Legislativo 1/2010, de 2 de julio". Finalmente, el apartado $3^{\circ}$ del precepto dispone que "las normas establecidas en la Ley 7/1985, de 2 de abril y en la Ley 27/2013, de 21 de diciembre, de racionalización y sostenibilidad de la Administración Local sobre los Consorcios locales tendrán carácter supletorio respecto a lo dispuesto en esta Ley".

Cabe destacar, de una parte, que se mantiene la remisión al Derecho de Sociedades introducida por la Ley de 2014, si bien, y a diferencia de lo dispuesto en el artículo 15.3 de esta disposición, se determina, como norma aplicable tras la propia LRJSP y, antes del Código civil, el ordenamiento autonómico. De otra, la declaración de supletoriedad en favor de la LBRL que se establece para los consorcios locales. Se trata, desde luego, de una previsión llamativa. Ante todo, por lo inusual de que una Ley básica se declare expresamente supletoria de otra de igual condición. Pero, sobre todo, por lo sorprendente que resulta que la norma supletoria sea la especial, la específicamente reguladora de unas Administraciones concretas, en vez de la general en la materia, como parece lo lógico en el juego propio de la supletoriedad. Quizás la norma, aunque dice lo que dice, quiso establecer algo diferente, que a los consorcios locales se les aplicarán las normas de la Ley 27/2013 en la medida en que no contradigan la nueva disposición legal ${ }^{62}$. De hecho, la propia LRJSP contiene en su disposición final $17^{\mathrm{a}}$, apartado $1^{\circ}$, un mandato de adecuación a la misma, en el plazo de un año a partir de su entrada en vigor, de todas "las normas estatales o autonómicas que sean incompatibles" con sus disposiciones. Habrá que esperar a ver que interpretación se efectúa del precepto.

62 La norma pasó en su tramitación parlamentaria prácticamente desapercibida. Tan sólo el Grupo parlamentario vasco formuló enmienda al precepto tanto en el Congreso (eenmienda número 48) como en el Senado (enmienda número 153), solicitando la supresión de este apartado "en atención a que su contenido excede el ámbito de lo básico al no dejar, prácticamente, margen alguno de desarrollo por las Comunidades Autónomas para en ejercicio de sus competencias en materia local regular los consorcios locales...". 


\section{El régimen de adscripción}

La LRJSP mantiene en su artículo 120 el régimen de adscripción del consorcio introducido en 2013 en la disposición adicional 20ª de la LRJ-PAC. Se sigue estableciendo, de esta forma, que los estatutos de cada entidad determinarán la Administración Pública a la que estará adscrita de "acuerdo con los siguientes criterios, ordenados por prioridad en su aplicación y referidos a la situación en el primer día del ejercicio presupuestario": a) Disponga de la mayoría de votos en los órganos de gobierno; b) Tenga facultades para nombrar o destituir a la mayoría de los miembros de los órganos ejecutivos; c) Tenga facultades para nombrar o destituir a la mayoría de los miembros del personal directivo; d) Disponga de un mayor control sobre la actividad del consorcio debido a una normativa especial; e) Tenga facultades para nombrar o destituir a la mayoría de los miembros del órgano de gobierno; f) Financie en más de un cincuenta por ciento, en su defecto, en mayor medida la actividad desarrollada por el consorcio, teniendo en cuenta tanto la aportación del fondo patrimonial como la financiación concedida cada año; g) Ostente el mayor porcentaje de participación en el fondo patrimonial; y h) Tenga mayor número de habitantes o extensión territorial dependiendo de si los fines definidos en el estatuto están orientados a la prestación de servicios a las personas, o al desarrollo de actuaciones sobre el territorio". Cuanto indicamos en el análisis de la citada disposición, puede darse aquí reproducido al haberse limitado el nuevo artículo 120.2 a recoger su contenido. Si acaso interesa remarcar que nos encontramos ante una disposición aplicable no sólo en el ámbito estatal, sino también en el autonómico y el local, lo que, como igualmente expusimos, determinó la impugnación de la norma ante el Tribunal Constitucional por el Gobierno de Cataluña. Aunque con ocasión de la tramitación parlamentaria de la Ley se propuso alguna enmienda que cuestionaba la que se calificaba como una "regulación cerrada y detallada que no deja margen a las Comunidades Autónomas para el ejercicio de su potestad de autoorganización ${ }^{63}$, hay que de decir, sin embargo, que, con carácter general, las Comunidades Autónomas parecen haber aceptado los criterios establecidos por el legislador estatal, como lo demuestra el hecho de que algunas de ellas hayan procedido a reformar las normas que establecían criterios de adscripción de los consorcios al objeto de adecuarlas al nuevo marco estatal ${ }^{64}$. Existe, no obstante,

${ }^{63}$ Se trataba concretamente de las enmiendas números 132 y 67 presentadas, respectivamente, en el Congreso y en el Senado por el Grupo parlamentario catalán.

64 Así ha sucedido en las Islas Baleares en donde la Ley 14/2014, de 29 de diciembre, de Finanzas de la Comunidad Autónoma, dio nueva redacción al artículo 85.4 de la Ley 3/2003, de 26 de marzo, de Régimen jurídico de la Administración de las Islas Baleares, al objeto de adecuar los criterios de adscripción que en el se disponían a la disposición adicional 20a de la LRJ-PAC introducida por la Ley 27/2013. Una nueva modificación de la norma, la producida por la Ley 12/2015, de 29 de diciembre, de Presupuestos generales de la Comunidad autónoma para 2016, vuelve a cambiar la redacción del precepto que pasará a disponer que la adscripción de los consorcios a la Comunidad se producirá "de acuerdo con los criterios 
alguna excepción significativa al respecto. Así, Cataluña cuyo Consejo de Garantías estatutarias en su Dictamen 24/2015, de 17 de diciembre, sobre la posible inconstitucionalidad de determinados preceptos de la Ley 40/2015, de 1 de octubre, ha apreciado que su artículo 120.2 puede incurrir, en efecto, en vicio de inconstitucionalidad al invadir las competencias autonómicas reconocidas en los artículos 151, 159 y 160 de su estatuto; esto es, las competencias sobre "las distintas modalidades organizativas e instrumentales para la actuación administrativa”, y sobre el régimen jurídico de las Administraciones Públicas y régimen local.

El consorcio, en cada ejercicio presupuestario y por todo este periodo, queda adscrito a la Administración que resulte de la aplicación de tales criterios, determinando cualquier cambio en la misma, según se establece ahora expresamente, la modificación de los estatutos "en un plazo no superior a seis meses, contados desde el inicio del ejercicio presupuestario siguiente a aquel en se produjo el cambio de adscripción". Con un carácter igualmente novedoso, el artículo 122 dispone que "a efectos de determinar la financiación por parte de las Administraciones consorciadas, se tendrán en cuenta tanto los compromisos estatutarios o convencionales existentes como la financiación real, mediante el análisis de los desembolsos efectivos de todas las aportaciones realizadas".

La Administración de adscripción determina el régimen jurídico de la entidad. La LRJSP sigue sin establecer una regla general expresa al respecto, aunque quizás pueda entenderse que lo hace indirectamente en su artículo 81 a favor del régimen de la Administración de adscripción ${ }^{65}$. El artículo 122 de la nueva Ley, en los mismos términos en los que hace la LRJ-PAC aún vigente, sí dispone que los consorcios quedarán vinculados por el "régimen de presupuestación, contabilidad y control de la Administración Pública a la que estén adscritos, sin perjuicio de su sujeción a lo previsto en la Ley Orgánica 2/2012, de 27 de abril”. Igualmente lo estarán, lo que si constituye una novedad respecto de la disposición de la que el precepto trae causa, a "las normas patrimoniales" de esta Administración. La LRJSP establece también en su artículo

que establece la legislación estatal básica relativa al régimen jurídico de las administraciones públicas y del sector público...". También Andalucía, en otro de los ejemplos que puede ofrecerse, ha modificado su ordenamiento a fin de incorporar a su ámbito los criterios de adscripción establecidos por el ordenamiento del Estado, como puede comprobarse en su Ley 6/2014, de 30 de diciembre, del Presupuesto de la Comunidad Autónoma de Andalucía para el año 2015, que da nueva redacción al artículo 12.3 de la Ley 9/2007, de 22 de octubre, de Administración de la Junta de Andalucía.

65 Este precepto, que tiene por objeto fijar los "principios generales de actuación del sector público", dispone en su apartado $3^{\circ}$ que "los organismos y entidades vinculados o dependientes de la Administración autonómica y local se regirán por las disposiciones básicas de esta ley que les resulten de aplicación, y en particular, por lo dispuesto en los Capítulos I y VI y en los artículos 129 y 134, así como por la normativa propia de la Administración a la que se adscriban". 
121 el régimen del personal consorcio en términos que no ofrecen variación alguna. Se sigue así determinando que este personal, que podrá ser tanto funcionario como laboral, "habrá de proceder exclusivamente de las Administraciones participantes" a cuya regulación quedará sujeto, no pudiendo sus retribuciones, en ningún caso, superar las establecidas para puestos de trabajo equivalentes en aquélla. La LRJSP mantiene, no obstante, la posibilidad, incorporada en la reforma de la disposición adicional $20^{a}$ de la Ley 30/1992 efectuada por la LO 6/2015, de que pueda contratarse personal directo "cuando no resulte posible contar con personal procedente de las Administraciones participantes en el consorcio en atención a la singularidad de las funciones a desempeñar" y siempre que "el Ministerio de Hacienda y Administraciones Públicas, u órgano competente de la Administración a la que se adscriba el consorcio", lo autorice "para el ejercicio de dichas funciones" ${ }^{" 6}$. Son numerosas, desde luego, las cuestiones de interés y dudas suscitadas por estas previsiones en las que, sin embargo, no podemos detenernos. Me remito, para su análisis, al excepcional estudio en la materia de F. CASTILLO BLANCO ${ }^{67}$.

Finalmente ha de tenerse en cuenta que el consorcio, en cuento entidad del sector público institucional, quedará sujeto las reglas que para todas las entidades de este tipo establece el artículo 81.2. Dispone este precepto que "todas las Administraciones Públicas deberán establecer un sistema de supervisión continua de sus entidades dependientes, con el objeto de comprobar la subsistencia de los motivos que justificaron su creación y su sostenibilidad financiera, y que deberá incluir la formulación expresa de propuestas de mantenimiento, transformación o extinción”.

\section{La creación del consorcio}

La previsión de normas sobre la creación de consorcios constituye claramente una de las pocas materias en las que la LRJSP viene a completar lo ya establecido por el Derecho anterior. Su artículo 123 diferencia, a este respecto, entre aquellas reglas

${ }^{66} \mathrm{El}$ artículo 121 del Proyecto de Ley del Sector Público fue objeto de algunas enmiendas. Así de las planteadas, tanto en el Congreso de los Diputados (enmienda número 133), como en el Senado (enmienda número 68), por el Grupo parlamentario catalán encaminadas a aumentar los supuestos en los que el consorcio pueda contratar directamente. Más contundente era la propuesta por el Grupo parlamentario "la izquierda plural" que proponía diversas modificaciones "destinadas establecer algunas garantías complementarias y derechos para este personal que la regulación actual no contempla" (enmiendas números 105 y 106 formuladas en el Congreso de los Diputados y 34 en el Senado de un senador de esta coalición integrado en el Grupo mixto). A esta petición se unió en el Senado el Grupo entesa pel progres de Catalunya" (enmienda número 127). Las enmiendas presentadas en esta cámara están publicadas en el Boletín Oficial de las Cortes Generales, Senado, núm. 585, de 25 de agosto

67 "La nueva regulación de los consorcios públicos: interrogantes y respuestas sobre el régimen jurídico de su personal”, Revista vasca de Administración Pública, número especial, 99-100, 2014, págs. 887 y siguientes. 
aplicables a todos los consorcios y las previstas concretamente para las entidades en las que participe la Administración del Estado. Con carácter general, el artículo 123.1 determina solo que "los consorcios se crearán mediante convenio suscrito por las Administraciones, organismos públicos o entidades participantes". La entidad surge pues con el convenio, lo que no está en la línea, por cierto, de lo establecido por algunas disposiciones autonómicas que mantienen que es la publicación de los estatutos la que determina su nacimiento y el reconocimiento de su personalidad jurídica ${ }^{68}$.

El artículo 123.2 establece, de otra parte, las reglas particulares aplicables a "los consorcios en los que participe la Administración General del Estado o sus organismos públicos y entidades vinculados o dependientes". Son las siguientes: a) Su creación ha de ser autorizada por la Ley, con lo que se prevé específicamente para esta entidad la regla establecida con carácter general para todos los organismos públicos en el artículo 91.2; b) El convenio de creación "precisará de autorización previa del Consejo de Ministros; c) La competencia para la suscripción del convenio, que no podrá ser objeto de delegación, corresponde "al titular del departamento ministerial participante, y en el ámbito de los organismos autónomos, al titular del máximo órgano de dirección del organismo, previo informe del Ministerio del que dependa o al que esté vinculado"; d) Del convenio "formarán parte los estatutos, un plan de actuación, de conformidad con lo previsto en el artículo 92 y una proyección presupuestaria trienal, además del informe preceptivo favorable del Ministerio de Hacienda y Administraciones Públicas"; y e) El convenio suscrito "junto con los estatutos, así como sus modificaciones serán objeto de publicación en el "Boletín Oficial del Estado"”.

Cabe reparar en que la Ley no fija realmente un procedimiento para la constitución de consorcios. Se limita a exigir un convenio que constituya el consorcio y a establecer algunos requisitos adicionales para los estatales. Ello es lógico dado que la regulación de ese procedimiento parece exceder de la competencia estatal en la materia.

\section{El contenido de los estatutos}

El artículo 124 regula, lo que no hace la disposición adicional $20^{\mathrm{a}}$ de la LRJ-PAC ni la Ley 15/2014, el contenido de los estatutos del consorcio. Además de establecer la Administración de adscripción de la entidad, ha de contar, "al menos", con los "siguientes aspectos": “a) Sede, objeto, fines y funciones; b) Identificación de participantes en el consorcio así como las aportaciones de sus miembros. A estos efectos, en aplicación del principio de responsabilidad previsto en el artículo 8 de la Ley Orgánica

68 Es el caso, por ejemplo, del artículo 80.4 de la Ley 5/2010. de 11 de junio, de Autonomía local de Andalucía. 
2/2012, de 27 de abril, los estatutos incluirán cláusulas que limiten las actividades del consorcio si las entidades consorciadas incumplieran los compromisos de financiación o de cualquier otro tipo, así como fórmulas tendentes al aseguramiento de las cantidades comprometidas por las entidades consorciadas con carácter previo a la realización de las actividades presupuestadas ${ }^{69}$; c) Órganos de gobiernos y administración, así como su composición y funcionamiento, con indicación expresa del régimen de adopción de acuerdos. Podrán incluirse cláusulas que contemplen la suspensión temporal del derecho de voto o a la participación en la formación de los acuerdos cuando las Administraciones o entidades consorciadas incumplan manifiestamente sus obligaciones para con el consorcio, especialmente en lo que se refiere a los compromisos de financiación de las actividades del mismo; y d) Causas de disolución”.

\section{El derecho de separación y la liquidación del consorcio}

Los artículos 125 y 126 regulan la separación del consorcio en términos sustancialmente coincidentes con los establecidos por la Ley $15 / 2014^{70}$, al igual que lo hace el

${ }^{69}$ Por su parte, la disposición adicional $10^{a}$ prevé que "cuando las Administraciones Públicas o cualquiera de sus organismos públicos o entidades vinculados o dependientes sean miembros de un consorcio, no estarán obligados a efectuar la aportación al fondo patrimonial o la financiación a la que se hayan comprometido para el ejercicio corriente si alguno de los demás miembros del consorcio no hubiera realizado la totalidad de sus aportaciones dinerarias correspondientes a ejercicios anteriores a las que estén obligados". Se generaliza así a todas las Administraciones Públicas una regla que la Ley de 2014 había previsto solo para la Administración del Estado en su disposición adicional $6^{\text {a }}$.

Estas previsiones son objeto de una valoración dispar por parte de E. NIETO. Así como le parece proporcionada a "la finalidad perseguida" la establecida en el artículo 124.b), la prevista en la disposición adicional no le merece un juicio positivo, toda vez que "va a significar, en la práctica, la paralización de la actividad consorcial por el incumplimiento de una de las entidades consorciadas de sus obligaciones de financiación del consorcio administrativo", cuando "existen medios menos drásticos para obligar a la entidad consorcial incumplidora al cumplimiento de sus obligaciones que no suponen la paralización del consorcio con el consiguiente perjuicio a los intereses públicos" que detalla ("Los consorcios administrativos", op. cit., págs. 2127-2128).

70 Una enmienda presentada en el Congreso de los Diputados el Grupo parlamentario de la izquierda plural propuso, sin éxito, una reforma del precepto al entender que el procedimiento previsto "sin mayores garantías, plazos ni condicionantes, puede producir una fuerte inestabilidad en los consorcios, con independencia de las indemnizaciones que pudieran proceder" (enmienda número 107). Un senador de esta fuerza política integrado en el Grupo mixto del Senado presentó en esta cámara una enmienda con idéntico contenido (enmienda número 35). Igualmente, el Grupo parlamentario entesa pel progres de Catalunya" formuló enmienda con igual finalidad (enmienda numero 128).

También el artículo 126 fue objeto de enmiendas. El Grupo parlamentario catalán propuso en el Congreso de los Diputados una enmienda (número 134), más tarde reiterada en el Senado (número 69), conducente a la supresión de la regla que hace depender la continuidad del consorcio de la presencia de, al menos, dos Administraciones o dos entidades u organismos públicos vinculados o dependientes de ellas. Por su parte, el Grupo parlamentario la izquierda plural propuso que se adicionara un nuevo apartado, el $3^{\circ}$, al artículo 126, a fin de que se remitiera a los estatutos la determinación de los efectos de la separación de un consorcio porque, según consideraba, "no es viable la regulación de un régimen único al margen 
127 en relación con la disolución de la entidad. Este precepto incorpora, no obstante, una novedad de interés que afecta al nombramiento del liquidador del consorcio. Recordemos que el artículo 14.2 de la Ley 15/2014 dispone al respecto que este debe ser nombrado por el máximo órgano del consorcio en el acuerdo de disolución, recayendo el cargo, a falta de acuerdo, en el administrador de la entidad. Frente a ello, la Ley de 2015 establece que "el máximo órgano de gobierno del consorcio al adoptar el acuerdo de disolución nombrará un liquidador que será un órgano o entidad, vinculada o dependiente, de la Administración Pública a la que el consorcio esté adscrito". Es decir, el liquidador sale del ámbito del consorcio para situarse en el de la Administración de adscripción, previsiblemente con la intención de asegurar la efectiva disolución de la entidad.

La LRJSP, a diferencia de la norma de 2014, determina además la responsabilidad del empleado público liquidador. Lo hace en el artículo 127.2 en los siguientes términos: "La responsabilidad que le corresponda al empleado público como miembro de la entidad u órgano liquidador será directamente asumida por la entidad o la Administración Pública que lo designó, quien podrá exigir de oficio al empleado público la responsabilidad que, en su caso, corresponda cuando haya concurrido dolo, culpa o negligencia graves conforme a lo previsto en las leyes administrativas en materia de responsabilidad patrimonial". Es la misma regla que la Ley establece para los organismos públicos estatales (artículo 97.2) y también para los empleados públicos en cuanto que miembros de los consejos de administración de sociedades mercantiles estatales o de los patronatos de las fundaciones del sector público (artículos 115 y 135). De esta forma, la responsabilidad del empleado público liquidador de un consorcio será asumida por la Administración o entidad que lo designó, sin perjuicio de las acciones que esta, en su caso, pueda ejercer contra el por la responsabilidad que le corresponda. Se abandona así el régimen privado-mercantil de responsabilidad de los liquidadores que se sustituye por el mas favorable previsto en el artículo 145 de la LRJ-PAC. Una solución que, según se ha dicho, "va en sentido contrario a los mas elementales principios de buen gobierno y buena administración"71.

El apartado $5^{\circ}$ del artículo 127 dispone finalmente que esa entidad en cuyo favor las entidades consorciadas pueden acordar una cesión global de activos y pasivos con

de las causas y efectos que motiven la separación, con independencia del objeto social del mismo y de las características del proyecto que gestionan, duración prevista y tiempo restante de actividad prevista para la consecución de sus fines" (enmienda núm. 108). Una petición que esta fuerza política reitera en el Senado a través de la enmienda presentada por uno de sus senadores integrado en el Grupo mixto (enmienda número 36), a la que se sumará entesa pel progres de Catalunya" (enmienda número 129).

71 E. MONTOYA, "Los instrumentos de colaboración pública-privada en la gestión de los servicios de interés general: El consorcio local y ¿su racionalización?”, op. cit. 
la finalidad de mantener la continuidad de la actividad y alcanzar los objetivos del consorcio que se extingue, ha de ser "otra entidad del sector público". Esta misma norma aclara además que "la cesión global de activos y pasivos implicará la extinción sin liquidación del consorcio cedente".

\section{BREVE CONSIDERACIÓN FINAL}

La nueva regulación de los consorcios presenta, como suele ocurrir ante cualquier reforma normativa, aspectos positivos y negativos. La mayor regulación de la entidad, que venían demandado autores como F. CASTILLO ${ }^{72}$, clarifica la normativa aplicable y garantiza una mayor transparencia desde el punto de vista económico y presupuestario, aunque supone también un menoscabo importante de los tradicionales espacios de libertad en los que nuestras Administraciones, en particular las locales, se han desenvuelto a la hora de crear entidades de esta naturaleza y establecer su régimen jurídico propio, lo que hizo del consorcio esa figura versátil, válida para el cumplimiento de los más diversos objetivos. Ello no ha de considerarse necesariamente negativo si bien es cierto que no ha contado, hasta ahora, con el juicio del todo favorable de la doctrina que destaca como es probable que de su mano se produzca un descenso significativo en la utilización de esta institución ${ }^{73}$.

Solo el transcurso del tiempo permitirá valorar en que medida este nuevo Derecho se muestra favorable para la entidad; en que medida, por el contrario, la imposición de los nuevos requisitos y controles establecidos se manifiesta contraria para la efectividad de una entidad que debe parte de su éxito a esa tradicional flexibilidad que la ha caracterizado. En cualquier caso, el consorcio administrativo se encuentra, como señala F. TOSCANO, en "una encrucijada"74 de la que confiemos salga con éxito.

\footnotetext{
72 "La nueva regulación de los consorcios públicos: interrogantes y respuestas sobre el régimen jurídico de su personal", op. cit., pág. 890.

${ }_{73}$ Véase, por todos, E. NIETO "La Ley de Racionalización y Sostenibilidad de la Administración Local y los consorcios administrativos", op. cit., págs. 379-380).

${ }^{74}$ Así en el título de su trabajo "El consorcio administrativo en la encrucijada", citado.
} 